\title{
Faculty Leaders Challenges and Strategies in Redesigning EdD Programs
}

\author{
Jill A. Perry, PhD \\ Associate Professor of the Practice \\ jillaperry@cpedinitiative.org \\ Debby Zambo, PhD \\ Professor Emerita and CPED Associate Director \\ debby.zambo@cpedinitiative.org \\ Emma Abruzzo, MeD \\ PhD Candidate and CPED Graduate Assistant \\ eta9@pitt.edu
}

\begin{abstract}
Producing change in higher education is not always easy or quick (Kennedy, et al., 2018; Perry, 2014a; Schuster \& Finkelstein, 2006; Tierney, 1998). Conferences provide faculty with exposure to new ideas, but that exposure is often not enough to produce programmatic and structural change. In addition to new ideas, faculty must also have the tools they need to navigate change and institutional resistance when introducing and implementing new ideas. Over the last decade or so, school of education faculty, guided by the Carnegie Project on the Education Doctorate (CPED) have worked to redesign the Education Doctorate and make it a professional practice degree. As a leader in educational change, CPED aims to reframe the EdD through both the cultivation of innovative ideas and the promulgation of those ideas across existing institutions and structures. CPED found faculty leaders to be necessary in creating institutional change, but also that the role of leader is a challenging one. Building upon earlier inquiries of faculty from CPED member institutions, this current study sought to discover more about the needs, challenges, and means for successful innovation implementation by EdD programmatic change leaders.
\end{abstract}

Keywords: education doctorate (EdD), change leader, CPED, redesign, resister, institutional, programmatic

\section{INTRODUCTION AND FOUNDATIONAL WORK}

Since its birth in 2007, CPED collaborated with faculty to rethink and redesign the $\mathrm{EdD}$, and to learn about that process along the way. In 2010, CPED was awarded a US Department of Education Fund for the Improvement of Post-Secondary Education (FIPSE) grant to determine how twenty-one of its original members of education changed their EdDs. Results from this cross-case study showed that even though CPED provided a Framework to help re/design programs, resistance and challenges confronted the change process at most institutions. For example, course work largely remained traditional in nature. That is, though some courses were redesigned, others remained focused on the needs of $\mathrm{PhD}$ students (e.g., research theory, inferential statistics) as opposed to the needs of practitioners. Courses reflected faculty experience and expertise in their own training and disciplines, which in most cases meant traditional $\mathrm{PhD}$-like thinking and the writing of a theoretical dissertation to jumpstart publishing careers. FIPSE data also showed the challenges faced by change leaders and faculty who were highly involved or leading redesign efforts. In this study, these leaders described their workload as more intense and more time-consuming (Perry et al., 2015). Meetings to share information and change courses and requirements reduced available time for other institutional obligations such as publishing and teaching. The same and more could be said for junior, tenure-track faculty chosen to lead or be involved in programmatic changes. These faculty members found themselves calling meetings and providing answers and rationales to more senior faculty with even fewer resources while having an increased imperative to publish. The study concluded that designated change leaders are forced to bear a cost relative to their time and career focus (Perry et al., 2015).

In 2014, Perry reported from a multiple-case study aimed at understanding how three faculty members from three different institutions facilitated change based on CPED's Framework. At the first institution, the faculty leader worked to bring together what she termed a "fragmented" faculty. Her work involved the usual planning, organizing, and communicating with various people, along with "putting out fires." This faculty leader admitted her role as change agent was a hard job and one for which she was not well prepared. Her colleagues recognized this as well and were not envious of her leadership role; as one faculty member stated, she had "all this responsibility without the authority." At the second institution, the faculty leader claimed his role was "to shake things up and to get these people either out or on board." This faculty leader spent a great deal of time "cleaning up" issues related to the program like student time to degree and the delivery and sequencing of courses. His efforts fell apart when he left and no successor could be found. At the third institution, the faculty leader organized working groups around the CPED design-concepts and invited faculty members to participate in working groups to redesign their existing EdD program. The groups met regularly, and the faculty leader was central in
New articles in this journal are licensed under a Creative Commons Attribution 4.0 United States License.

This journal is published by the University Library System of the University of Pittsburgh as part of its D-Scribe Digital Publishing Program and is cosponsored by the University of Pittsburgh Press.

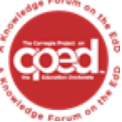

This journal is supported by the Carnegie Project on the Education Doctorate: A Knowledge Forum on the EdD (CPED) cpedinitiative.org

impactinged.pitt.edu Vol.5 (2020) DOI $10.5195 /$ ie. 2020.143
ISSN 2472-5889 (online) 
organizing discussions and work. Still, the process unfolded slowly.

Two key findings emerged from Perry (2014b) that grew the findings from the FIPSE study. First, in order to be successful agents of change, faculty in leadership roles necessitate top administrative support in a top-down/bottom-up change process. Second, there exists a complexity and discomfort between faculty leaders and their colleagues during the process of choosing and implementing change efforts in their EdD programs. Given both of these study results, CPED planned its next investigation to serve as a follow-up and extend this work with a new group on individuals - its Delegates Council, or faculty members who serve as institutional change leaders appointed to work with CPED leadership to review, revise and update the CPED Framework, adopt policies for the implementation of the Framework, support of institutional members, and more.

\section{THEORETICAL FRAMES}

Two theoretical frames informed our study as we sought to uncover the needs, challenges and successes the Delegate Council faculty faced and how they addressed them. The first was Everett Rogers' (2003) diffusion of innovation which provides a comprehensive view of "the process by which an innovation is communicated through certain channels over time among members of a social system" (p. 10). On a larger scale, Rogers' theory can support understanding of how CPED ideas are adopted and how institutions change. In this study, the Rogers model provided insights about the action faculty take when acting as change agents. These actions include:

1. Developing a need for change through awareness;

2. Establishing an information-exchange relationship or rapport between the change agent and those needed to make the change;

3. Diagnosing and analyzing problems and determining why the way things are needs to be different;

4. Creating an intent to change by motivating interest in the innovation;

5. Translating intentions to change into to actions;

6. Stabilizing adoption and preventing discontinuance at the implementation stage; and

7. Achieving a terminal relationship. The change agent should seek to develop individual's capability to be their own change agent (p. 337).

In her study on faculty change agents, Perry (2014b) found that these seven characteristics were not enough to fully understand the role of faculty as change agents in complex institutions like higher education. She adopted a second lens, Meyerson's Tempered Radicals Framework (2003), to explore more deeply how grassroots leadership plays out in higher education. Meyerson's framework described individuals who both identify with and are committed to their institutions, but who are also committed to a cause or movement that is "fundamentally different from and possibly at odds with the dominant culture of their organization" (Meyerson \& Scully, 1995, p. 186). This type of change agent aspires to create positive change but has no formal authority to do so. Therefore, as they work to change colleague mindsets and policy structures in organizations that can be inherently resistant to change, they temper their strategies to limit personal discomfort. Tempered radicals, as these grassroots leaders are called (Meyerson, 2003), rely on a variety of strategies that do not necessarily follow a formal step-by-step process, as Rogers (2003) suggested, but rather offer ways to tackle obstacles and resistance while protecting themselves. Such strategies defined in Meyerson's (2003) framework are grouped into three levels-the individual or psychological level (including actions focused on self-motivation, identity, and resilience), at the group or social psychological level (including strategy, tactics, power dynamics to motivate change with groups) and at the organizational level (including leadership development, group formation, structural and cultural change). In this study, we utilized both theories to gain stronger understanding of how CPED faculty members were addressing issues related to redesigned EdD programs.

\section{PARTICIPANTS AND STUDY DESIGN}

A study of the members of the CPED Delegates Council was conducted through the administration of a qualitative survey and analysis of the subsequent results. Participants were CPED Delegates, individuals appointed by their Dean to serve as the primary contact between CPED and their home institution, and who most often serve as one of the lead faculty in their EdD program re/design. The Delegates Council was established in 2019 to enhance the reciprocal relationship between CPED and its members. Prior to their first meeting, CPED leadership led an investigation into the dilemmas faced and remedies implemented by Delegates at their institutions. To accomplish this an open-ended survey was sent to each Delegate to learn about the following questions:

Q1: What is a dilemma that you face in implementing the CPED Framework at your institution?

Q2: What have you done already to try and remedy or manage the dilemma?

Surveys were sent to 107 individuals assigned to be CPED Delegates for their institutions. IRB consent statements were included in the survey and completion of the survey served as consent to participate. 63 surveys were returned for a response rate of $59 \%$. Data were analyzed using a qualitative, grounded research approach (Strauss \& Corbin, 1998). Data were placed into a spreadsheet and instances of commonalities and differences were noted and coded. Then coded data were categorized to understand each code's properties and dimensions (Strauss \& Corbin, 1998). Data for each category were then reunited to form a bigger picture (Glaser \& Strauss, 1967). This deductive process continued until saturation (Miles \& Huberman, 1994).

\section{FINDINGS AND DISCUSSION}

Four dilemmas were described by respondents-faculty resistance, challenges redefining the dissertation, demands of the redesign process, and student issues. In the following, we will describe each of these dilemmas, the challenges they cause Delegates, and the strategies they employ to address them. In doing so, we will apply the theoretical frames of Rogers (2003) and Meyerson (2003) to better describe and understand the actions taken by Delegates in their capacity as leaders of institutional change efforts.

\section{Faculty Resistance}

The most commonly described dilemma faced by Delegates in implementing CPED's Framework was the prevalence of 'Faculty 
Resisters' at their institutions. Faculty resisters fall into one of the following ideological persuasions: they not understand the need for change, they do not believe change should be implemented, or they disagree on just what that change should entail. Faculty resisters were most frequently described as individuals who hold $\mathrm{PhDs}$ and who largely did not see the merits of redesigning courses and milestones to be different than traditional PhD programs. These resisters did not buy-in to the CPED Framework. Their perspectives are stubbornly held and manifest in a propensity to maintain the status quo in a way that is not productive for redesigning the EdD. Resisters may hold a deficit view of the EdD, understanding it as a PhD-lite, or a doctorate of lower quality and rigor. They appeared to have a difficult time accepting the $\mathrm{EdD}$ as a practitioner degree rather than a theoretical/research degree. Resistance to change was observed to be both overt and covert. Some faculty plainly voiced their opposition in meetings and when serving on design committees. Others more covertly resisted through the construction of roadblocks. The roadblocks were both social and administrative. An example includes faculty members agreeing to change courses, but then continuing to teach in traditional ways with little connections to practice.

Despite being one of the most difficult challenges faced, Delegates have worked to engage their resisting colleagues. From a Rogers (2003) frame, we see Delegates enacting four of the change agent actions: Developing a need for change through awareness; Establishing an information-exchange relationship or rapport between the change agent and those needed to make the change; Diagnosing and analyzing problems and determining why the way things are needs to be different; and Creating an intent to change by motivating interest in the innovation. An example of these actions includes developing communication strategies -- continuous face-tomeetings, discussions, reviews, and retreats, and advertisements, articles, and resources. Another example includes making structural changes to programs such as course names, developing handbooks, or creating admissions tactics. A third example is the creation of professional development opportunities for their colleagues.

From a Meyerson (2003) frame, we can understand the Delegate role as change agent more fully. At the individual level of the Tempered Radical Framework, the continuous efforts of these faculty members speak to the notion of resilience in the face of resistance. Delegates seek out new and various ways to reach out to their colleagues and share what they have learned at CPED convenings to move the redesign effort forward. They remain motivated by their commitment to the $\mathrm{EdD}$ as a practitioner degree. Yet they often struggle with identifying as the leader, or most knowledgeable about the change effort, and continue to seek information and professional development for themselves. At the group or social psychosocial level, they seek to learn strategies and tactics to temper their role as a leader of change and become collaborative. They attempt to build consensus through group discussion and sharing of ideas. In this way, they feel they are reducing some of the criticism and cynicism. Finally, at the organizational level, small structural changes to programs seek to create a culture that slowly shifts towards understanding the EdD as a professional practice degree.

\section{Redefining the Dissertation}

The second most prevalent dilemma Delegates face in implementing CPED's Framework at their institution is in redefining the dissertation. CPED asserts that the EdD dissertation should be termed and understood as a Dissertation in Practice (DiP), or a scholarly endeavor that impacts a complex problem of practice (CPED, 2010). Misconceptions about the purpose, format, and structure of the DiP are key to the challenge of redefining the dissertation. Delegates report that their colleagues have difficulty discerning how and why a DiP differs from a traditional $\mathrm{PhD}$ dissertation. Their colleagues lack understanding about how to mentor and advise EdD students differently from traditional $\mathrm{PhD}$ students particularly around the dissertation experience. The degree and type of advice and support regarding the dissertation's process and expectations varies between and within programs and institutions providing faculty with uneasy ground to stand upon. And often, programs lack documents to guide, support, and make EdD dissertation work consistent.

Delegates have worked to support their colleagues and students in understanding the CPED definition and implementation of the DiP. Through Rogers (2003), we see Delegates enacting four of the change agent actions: Developing a need for change through awareness; Diagnosing and analyzing problems and determining why the way things are needs to be different; Creating an intent to change by motivating interest in the innovation; and Translating intentions to change into to actions. Actions taken include creating informational documents, ongoing support for colleagues and consistency in message about the DiP, redesigning of course work to support early development of the DiP, investigating and implementing new and different approaches to the traditional dissertation experience, and teaching colleagues to mentor in different ways.

With this dilemma we also see Delegates acting in tempered ways at all three levels of strategic change. As individuals, Delegates identify as the resource for change though recognize that they don't always have the answers. They often seek out more information to support their colleagues. They have worked at the group level collaborating with colleagues to change courses, share about new approaches, and collaborate on new advising models. Delegates create change at the organizational level, in part, through structural changes to courses and formats of DiPs.

\section{Demands of the Redesign Process}

The third dilemma Delegates face in implementing CPED's Framework at their institution is the speed and breadth of the redesign process. Delegates said they were often "building the plane while flying it" and "making decisions [about (re)design] in the midst of the program." Overlaying this sense was the struggle to gain a shared understanding across faculty colleagues of the CPED Framework and how it applied to program redesign processes. Additionally, Delegates struggled to develop continuous improvement processes as part of the redesign. Further complicating the redesign process, Delegates reported that institutional roadblocks came in a variety of forms and at various points in the redesign process often causing need for quick action or slowing the process.

Delegates worked to overcome the struggles of program redesign. Again, drawing on Rogers' (2003) frame, Delegates continued to enact change agent actions to address these dilemmas. Namely, developing a need for change through awareness, establishing an information-exchange relationship or rapport between the change agent and those needed to make the change, diagnosing and analyzing problems and determining why the way 
things are needs to be different, creating an intent to change by motivating interest in the innovation, and translating intentions to change into to actions. These actions included having regular meetings, conversations and trainings with faculty colleagues and using CPED's resources-websites, readings, colleagues-to support those efforts. They created templates and documents to share with colleagues and students, developed communications to disseminate redesign efforts.

Meyerson (2003) frames Delegates as individuals who identify with the role of change agent, having an openness to continuously improve their redesign process. This identity guides their work at the group level where they share and use CPED's resources (website, articles, books), set aside time to work together to develop a shared understanding of the EdD based on CPED's vision, map curricular and experiential sequences around CPED's Framework, redesign courses to meet students' needs, share and align their syllabi, and create documents describing different options for DiPs. At the organizational level, the Delegates also felt it was important to keep administrators updated about redesign efforts and maintain close working relationships.

Overall, despite feeling that change was slow and time consuming, they did see progress with programs moving in the right direction. They reported gains such as program clarity, new elements, respect for the EdD, greater student learning, and influential Dissertations in Practice. Administratively, they saw improved enrolment and completion rates. Personally, they felt they were building partnerships with colleagues and finding opportunities for publications.

\section{Student Issues}

The fourth dilemma Delegates face focuses on issues with students. Key challenges were issues related to the DiP issues that arise when students' change their work context (which is often the place where the DiP is conducted) and the challenge of working with practitioners who lacked quality, writing skills.

Delegates work to address these student issues regularly. Delegates enacting four of the change agent actions: Establishing an information-exchange relationship or rapport between the change agent and those needed to make the change; Diagnosing and analyzing problems and determining why the way things are needs to things are needs to be different; and Translating intentions to change into to actions (Rogers, 2003). Actions include listening to students and stakeholders, closing divides between practitioners and researchers, continuing to redesign the program, re-scheduling and redesign courses, mentoring, and dissertations to meet students' needs, and providing support for improved writing skills.

Delegates as individuals take on more profound advisor identity supporting students in more ways, during unusual time (weekends, nights) and in shorter timeframes. At the group level, Delegates are working to bring groups of academics, practitioners and stakeholders together through information strategies focused on defining the EdD as a professional practice degree. At the organizational level, they are shift understanding and culture around what it means to be a faculty member in EdD programs and practitioners (Meyerson, 2003).

\section{CONCLUSION}

Over the last thirteen years, many CPED faculty acting as change agents at their home institutions have worked to reimagine the EdD and to make it a strong professional practice experience for those who lead educational organizations. Using these faculty members' input, CPED has created a Framework aimed at distinguishing the EdD from the PhD by giving the $\mathrm{EdD}$ its own equally important, identity. Still, as data from this study shows, reframing the EdD has not been easy, straightforward, or fast. We learned much of what we have seen over the years - Delegates face implementation hurdles that stem from their peers, the re/design process, and new dissertation forms and functions. Such hurdles are the result of the traditions and norms of higher education that often make organizational change difficult at the faculty level.

As Delegates continue to face dilemmas around the re/design of the $\mathrm{EdD}$ and as they act in a tempered manner to create change, they continue to look to CPED to provide more support and information. As a conclusion to this study, we offer a bit of experience and knowledge as leaders of CPED on addressing some of the above challenges.

\section{Engaging Resisters}

If faculty members hold $\mathrm{PhDs}$ and have little connection to practice, they may not see or understand the need for change to the EdD. To shift and guide their understanding of the EdD, faculty leaders can engage tempered strategies such as providing evidence and clear information for discussion across all faculty members. To some degree CPED Delegates are doing this through varied communication (e.g., meetings, discussions, resources, readings etc.). However, we stress that the content of the communication should be substantive and persuasive and allow resistant faculty the opportunity to build their own understanding through discussion and debate. Examples include:

- Data. Offering data and information about the current status of the EdD program (enrollment, completion rates, faculty and student perspectives, where students go after they graduate). Do the data show a successful program, engaged students, and competent graduates?

- Literature. Articles and research that explain the history of the EdD and help faculty understand why change is needed. Three good ones to start with are:

- Reclaiming education's doctorates: A critique and a proposal by Shulman, et al. (2006)

- Rebooting the EdD by Wergin (2011)

- What does history reveal about the education doctorate? by Perry (2012)

As the work continues, additional literature (such as those about dissertation options) can be introduced to build conversations and foster change ideas.

- CPED Framework. Introducing the CPED Framework and information about CPED's mission, history, and accomplishments is essential to creating change. Offering examples of what CPED member institutions are doing to implement the Framework and what these examples might mean for EdD programs are basis for change conversations. 
Communication that includes these types of information and opportunities to discuss and debate can help faculty resisters understand why EdD programs need to change. Substantive communication should help faculty understand that their courses and dissertation work prepared them for their roles at the university, which is not the goal of EdD students who want to remain in practice and improve educational organizations and problems.

\section{Support and Buy-in from Peers, Networks, and Stakeholders}

Our findings demonstrate that this work is very challenging to do alone. Despite often being both dedicated and resilient (Meyerson, 2003), Delegates faced the most difficulty when they experienced feelings of dissonance from their networks, colleagues, and administration. For that reason, it is strongly advised that change leaders build a supportive team when carrying our redesign efforts. This team may be at their institution and/or can include individuals and institutions from outside of the institution such as:

- $\quad$ Other faculty members: Engaging colleagues in the change process, whether through voicing opinions or serving in committee roles, is important if buy-in and sustainability are to be achieved. Additionally, creating like-minded peer networks is important for the change leader. These may be faculty in other departments that offer EdDs or simply critical friends, peers who will provide honest, open feedback and support.

- External networks: CPED members, CPED team members who can answer vital questions about resources, facilitation services, and professional development opportunities. These colleagues can also offer critical feedback and general support in challenging times.

- External stakeholders: Key to successful EdD program re/design is listening to the voices of those who will both attend the university and gain benefit from its work (e.g., school and organizational administrators, educators, parents, students). Local contexts and communities should be engaged in $\mathrm{EdD}$ program (re)design.

\section{Action and Sustainability}

We learned from this study and previous ones that the role of the faculty leader is important but not enough for sustainable change within schools of education. Sustainable change takes a village (Rogers, 2003). Therefore, to enact and sustain change and continuous improvement, faculty leaders need support from the following:

- Deans. School deans must be on board to support faculty leaders. In their role as opinion-leaders (Rogers, 2003), deans can champion and set a vision for change. They have the ability to support the faculty leader with policy and evidence-based decisions and support them with resources such as course releases, graduate assistants, and travel. We suggest that all faculty leading change keep their deans informed about their work, about changes in the field and other institutions, and about what they learn from CPED and beyond as they engage in this process
- $\quad$ Faculty working groups. The re/design of a degree should not be an assignment given to a single faculty member. The integral nature of EdD courses and the need for alignment and collaboration across courses requires a backwards mapping process (Perry, et al., in press) that should be done with groups of facultyboth those who teach and those who advise in the program. We suggest having a faculty committee that oversees the $\mathrm{EdD}$ and working groups that manage the various aspects of the program. These faculty can also help in informing peers about the importance of the work to spread change more effectively (Rogers, 2003).

- $\quad$ Students. Current students and alumni are great resources for understanding what programs need. Surveys and focus groups with alumni can support learning about what needs to change. Connection with current students can support on-going change and build student buy-in to change. We recommend that students be made aware of the intention and action to re/design the degree as a professional practice degree. For CPED-influenced programs, students should know they are part of a change movement that is aimed at improving their profession.

- Administration. Having all levels of administration involved is important. We recommend that faculty and deans regularly communicate with upper-level administration about the re/design and vision for the EdD. We suggest that admission folks be trained about the vision, goals, and types of students the EdD program is seeking. Support staff should also be aware so that students receive correct information.

These tempered collaboration strategies across these various groups will help to create change at the organizational level (Meyerson, 2003).

Change in higher education is incredibly difficult, but it is doable. CPED members have shown this to be true. As our membership grows, we encounter old ways of thinking. But we have a history of supporting change in schools of education and are prepared to support members with our years of experience and resources in the continued effort to improve the $\mathrm{EdD}$ and make it the professional practice degree in education.

\section{REFERENCES}

Adler, J. \& Karlsberg, R. (2005),7 Strategies for Sustained Innovation. Retrieved 6 March 2020 from https://innovationmanagement.se/imtoolarticles/7-strategies-for-sustained-innovation/

Carnegie Project for the Educational Doctorate (CPED). (2010). Design concept definitions. Retrieved from http://cpedinitiative.org

Glaser, B., \& Strauss, A. (1967). The discovery of grounded theory. 1967. Weidenfield \& Nicolson, London, 1-19.

Kennedy, B., Altman, M., \& Pizano, A. (2018). Engaging in the battle of snails by challenging the traditional dissertation model. Impacting Education (3). DOI 10.5195/ie.2018.27

Meyerson, D. E. (2003). Tempered radicals: How everyday leaders inspire change at work. Boston, MA Harvard Business School Press.

Meyerson, D., \& Scully, M. (1995). Tempered radicalism and the politics of ambivalence and change. Organization Science, 6(5), 585-600.

Miles, M. B., \& Huberman, A. M. (1994). Qualitative data analysis (2nd ed.). Thousand Oaks, CA: Sage.

Perry, J.A. (2012). What does history reveal about the education doctorate? In Macintyre Latta, M. \& Wunder, S. (Eds.). Placing Practitioner Knowledge 
at the Center of Teacher Education: Rethinking the Policy and Practice of the Education Doctorate. Charlotte: Information Age Publishing.

Perry, J.A. (2014a). The CPED Argument: A Counter-Response. UCEA Review, 22-24.

Perry, J.A. (2014b). Changing schools of education through grassroots facultyled change. Innovation in Higher Education 39(2), 144-168

Perry, J.A., Zambo, D. \& Wunder, S. (2015). Understanding How Schools of Education have Redesigned the Doctorate of Education. Journal of School Public Relations, 36, 58-85.

Rogers, E. M. (2003). Diffusion of Innovations (5th ed.). New York, NY: The Free Press

Schuster, J., \& Finkelstein, M. (2006). The American faculty: The restructuring of academic work and careers. Baltimore, MD: Johns Hopkins Press.

Shulman, L. S., Golde, C.M., Bueschel, A.C., \& Garabedian, K.J. (2006). Reclaiming education's doctorates: A critique and a proposal. Educational Researcher, 35(3), 25-32.

Strauss, A. \& Corbin, J. (1998). Basics of Qualitative Research: Techniques and Procedures for Developing Grounded Theory (2nd ed.). Thousand Oaks, CA: Sage Publications.

Tierney, W.G. (1998). Organizational culture in higher education: Defining the essentials. The Journal of Higher Education, (59),1, pp. 2-21.

Wergin, J.F. (2011). Rebooting the EdD. Harvard Educational Review, 81(1), 119-140. 